\title{
A INFLUÊNCIA DA LÍNGUA PORTUGUESA NA PRODUÇÃO DA LIBRAS NA PERSPECTIVA DE TRANSLINGUAGEM
}

\author{
THE INFLUENCE OF PORTUGUESE LANGUAGE ON THE PRODUCTION \\ OF LIBRAS IN THE TRANSLANGUAGING PERSPECTIVE
}

\section{LA INFLUENCIA DE LA LENGUA PORTUGUESA EN LA PRODUCCIÓN DE LA LENGUA LIBRASEN LA PERSPECTIVA DE TRANSLENGUA}

\author{
Claudney Maria de Oliveira-Silva* \\ Neuma Chaveiro ${ }^{* *}$
}

\begin{abstract}
Resumo
O objetivo deste artigo é trazer reflexões sobre a influência da língua portuguesa na produção da libras na perspectiva da translinguagem, uma vez que o contato dessas línguas resulta em uma produção que excede os limites conceituais tradicionais sobre os fenômenos de línguas em contato. É um estudo de caso de caráter interpretativista realizado por meio da análise de um texto escrito em língua portuguesa por duas alunas surdas falantes de libras. Os resultados revelaram a influência da língua portuguesa na libras por meio de elementos linguísticos, próprios da língua portuguesa e inexistentes ou não aparentes na libras, incluídos nas falas das alunas durante as discussões para a produção do texto. A análise das discussões também revelou que as alunas, além de escolher usar a modalidade mais apropriada (escrita ou sinalizada) e mesclar as línguas, se envolveram em práticas discursivas múltiplas para construírem conjuntamente significados e identidades sociais em seus mundos bilíngues, ou simplesmente, translinguaram.
\end{abstract}

Palavras-chave: Bilinguismo. Português. Libras. Translinguagem.

\section{Introdução}

A libras ${ }^{1}$, língua de sinais brasileira, é uma das várias línguas que convivem com a língua portuguesa no Brasil ${ }^{2}$. Apesar das diferenças nas modalidades de produção e recepção - a primeira é uma língua gesto-visual e a segunda, oral-auditiva - o contato entre ambas tem resultado na presença de alguns elementos da língua portuguesa escrita nos sinais da libras.

\footnotetext{
* Doutora em Ciências da Saúde pela Universidade Federal de Goiás. Professora do Curso de Letras: Libras da Faculdade de Letras da UFG; E-mail: neumachaveiro@gmail.com

** Doutora em Linguística pela Universidade Federal de Goiás. Professora do Curso de Letras: Libras da Faculdade de Letras da UFG; E-mail: claudney@terra.com.br
} 
Neste artigo, propomos uma discussão sobre a influência da língua portuguesa na produção da libras, orientada principalmente pela concepção da translinguagem (GARCÍA, 2009), uma vez que o contato dessas línguas resulta em uma produção que excede os limites conceituais tradicionais sobre os fenômenos de línguas em contato. Para a autora, translinguagem são as práticas discursivas múltiplas nas quais os indivíduos bilíngues se engajam a fim de significar seus mundos bilíngues. Este trabalho é resultado da análise criteriosa da observação da produção em libras de duas alunas surdas durante a realização de uma tarefa colaborativa de produção de um texto escrito em língua portuguesa. O objetivo foi verificar a influência da língua portuguesa na libras, aparente na fala das alunas, durante as discussões para a produção do texto sob os pressupostos da translinguagem. A mudança de código, o empréstimo, a transferência e a datilologia são movimentos linguísticos de uma língua para outra a partir do contato de ambas, ao passo que a translinguagem, não só leva em conta esses movimentos linguísticos como, principalmente, enfatiza o potencial das zonas liminares linguísticas dos bilíngues como um instrumento mediador de sentido.

Neste trabalho, primeiramente, apresentamos os pressupostos teóricos sobre bilinguismo, os fenômenos resultantes do contato das línguas e o conceito de translinguagem que orientaram a análise dos dados e com os quais nos afiliamos. Em seguida, explicamos os procedimentos metodológicos e os critérios utilizados para a análise dos dados. Na seção de análise de dados, identificamos os movimentos linguísticos, buscamos explicar a sua ocorrência e apresentamos evidências da translinguagem na produção linguística do surdo. Por fim, esclarecemos que não há conhecimento, da nossa parte, de trabalhos anteriores que abordem a educação bilíngue dos surdos na perspectiva da translinguagem.

\section{Aspectos teóricos}

A situação linguística do Brasil é complexa. Ainda que haja duas línguas oficialmente reconhecidas, o português e a libras, de acordo com dados do Instituto de Patrimônio Histórico e Artístico Nacional (IPHAN) ${ }^{3}$, mais de 250 línguas são faladas no Brasil, mas somente duas são oficialmente reconhecidas, o português e a libras, e ainda assim, é grande o número de pessoas que consideram o Brasil um país monolíngue. Dentro desse imaginário, a discussão sobre a educação bilíngue dos surdos não é tarefa simples e os conceitos e pressupostos que a embasam geralmente 
são apresentados sobrepostos ou não claramente definidos. Daí a necessidade de explicitarmos o aporte teórico que nos possibilitou realizar este trabalho.

\subsection{Bilinguismo}

À primeira vista, definir o bilinguismo parece ser uma tarefa fácil: "bi-” significa dois e "-língue", língua. Assim, uma pessoa bilíngue é aquela que fala duas línguas. No entanto, a noção de bilinguismo é ampla e por isso, mais difícil de conceituar. Em um extremo, temos a visão perfeccionista de Bloomfield (1933) ${ }^{4}$ do ser capaz de falar como o nativo em ambas as línguas; no outro, a perspectiva reducionista de Macnamara (1967) do ser minimamente competente em falar, ouvir, ler e escrever em uma língua diferente da sua língua nativa. A variação entre um extremo e outro é determinada levando-se em consideração aspectos como o grau de proficiência, uso e função das línguas, alternância de códigos e interferência das línguas (MACKEY, 2000).

Para Grosjean (2010, p. 4), bilíngues são "pessoas que usam duas ou mais línguas (ou dialetos) no seu cotidiano", concentrando as questões do bilinguismo no seu uso e não na fluência com que são faladas. Nesse sentido, levamos em consideração as explanações de Mello (2010) em relação às características do indivíduo (graus variados de competência e diferentes modos de fala), às características sociológicas do contexto (local, participantes, situação, tópico) e à função da interação, e é nesse sentido que visualizamos o bilinguismo da pessoa surda, onde a competência bilíngue está sempre em processo de desenvolvimento em uma daquelas características.

$\mathrm{Na}$ educação bilíngue, defende-se a ideia de que as duas línguas em questão devem ser aprendidas de forma independente uma da outra (JACOBSON, 1983) bem como de forma simultânea (ZENTELLA, 1997). Em várias comunidades de falantes de espanhol nos Estados Unidos, onde as crianças são expostas simultaneamente às duas línguas, espanhol e inglês, é muito freqüente a mudança de código e isso, segundo Zentella (1997), raramente provoca confusão linguística.

Sayer (2013) retoma a Nova Abordagem Concorrente (JACOBSON; FALTIS, 1990) para a educação bilíngue que deixa claro o objetivo pedagógico para a mudança de código na sala de aula, dá exemplos para distingui-la de abordagens que exigem uma separação de línguas estrita ou daquelas que as misturam de forma desordenada. Nessa mesma direção, Mackey (2000) sugere que a mudança de código deve ser estudada a 
fim de se saber como, com qual frequência e em que condições o indivíduo alterna de uma língua para outra.

Sabemos que a mudança de código sinaliza uma mudança na posição do falante, quer seja para reduzir a distância social e reforçar a solidariedade ou para demonstrar status ou autoridade e aumentar a distância social (GOFFMAN, 1981), e que as línguas são vistas como opções que os falantes utilizam diante das pessoas com quem fala, segundo a função que podem desempenhar e no contexto em que estão inseridas (QUADROS, 2005).

Gumperz (1982) define mudança de código como a justaposição no mesmo discurso de passagens de discurso pertencentes a dois sistemas ou subsistemas gramaticais diferentes. Para Groesjean (2010, p.51) mudança de código “é o uso alternado de duas línguas, isto é, o falante realiza uma completa mudança para outra língua de uma palavra, frase ou sentença, e em seguida volta para a língua base”.

A mudança de código é vista por algumas pessoas como um descuido com a língua, mas na verdade representa uma capacidade bilíngue especial e não configura uma suposta deficiência linguística nem preguiça dos falantes (POPLACK, 1980), ao contrário, tem sido visto como uma habilidade linguística sofisticada e uma característica da fala de bilíngues fluentes (AUER, 1995).

Acreditar que algumas ideias ou conceitos são simplesmente melhores quando expressos em outra língua, preencher a necessidade linguística de uma palavra ou expressão, marcar a identidade de um grupo, excluir alguém, elevar o seu status, mostrar expertise, são algumas das razões normalmente apresentadas pelas pessoas bilíngues para mudar de código durante seu discurso (GROSJEAN, 2010).

Outro fenômeno de contato entre línguas é a adoção de elementos externos à língua de origem. Na literatura, diferentes termos são adotados para definir a percepção desse fenômeno entre os autores. Nascimento (2011) apresenta alguns desses termos e os autores que os adotam: para Haugen (1972, p. 82), as incorporações apresentam-se como "transferências" e reprodução do modelo original; para Weinreich (1974, p. 1) o termo "interferência" explicita o rearranjo dos padrões resultantes da introdução de elementos estrangeiros nos domínios mais estruturados da língua; Thomason e Kaufman (1988, p.37) afirmam que o "empréstimo" é a incorporação de aspectos estrangeiros na língua nativa, que é mantida, embora alterada pelo acréscimo dos traços (características) incorporados. 
De acordo com Carvalho (1989) o motivo mais comum que leva o falante ao empréstimo é a ausência de uma palavra ou traço linguístico em uma língua, obrigandoo a usar palavras de outra língua para expressar um determinado conceito. Garcia e Wei (2014) utilizam o termo "empréstimo" para designar o uso de itens lexicais individuais de outras línguas, mas ponderam que desde 1980, estudos sobre transferência, empréstimo e interferência tendem à denominação "influência translinguística", que permite a inclusão do discurso intercultural e cross-cultural, da pragmática e das motivações internas e externas nos estudos sobre línguas em contato. Neste trabalho, optamos também pela utilização do termo "empréstimo".

\subsection{Empréstimo nas línguas de sinais}

De acordo com Lane e Grosjean, “sinais são comparáveis às palavras nas línguas orais" (1989, p.104, apud NASCIMENTO, 2011). Segundo Faria-Nascimento (2009), os sinais são formados a partir da combinação da configuração de mão (CM: possíveis formas e posições que as mãos e os dedos adquirem na realização dos sinais), ponto de articulação (PA: lugar onde incide a mão predominante), movimento (MOV), orientação de palma (OP: direção para onde está voltada a palma da mão) e expressão facial/corporal (EFC). E são esses os cinco parâmetros fonológicos dos sinais.

Desses parâmetros, a CM tem papel importante na realização dos empréstimos da língua portuguesa na libras, por meio da datilologia ou soletração manual. A soletração manual "não é a representação direta do português: é uma representação manual da ortografia do português, envolvendo uma sequência de configurações de mão que tem correspondência com a sequência de letras escritas do português" (QUADROS; KARNOPP, 2004, p. 88), também conhecida como alfabeto datilológico.

A datilologia ou digitação em língua de sinais pode ser comparada à soletração em línguas orais: faz-se a correspondência de uma letra da grafia alfabética de uma língua oral com uma configuração de mão de uma língua de sinais, que pode variar de uma língua para outra (QUADROS e PIMENTA, 2006). É utilizada em situações em que não se tem certeza se o interlocutor conhece um dado sinal, quando não há um sinal para o termo correspondente em português presente no discurso, para nomes de pessoas, para apresentar um novo sinal ou um novo conceito, etc. Por essas razões, a datilologia em si não é considerada um tipo de empréstimo, podendo apenas servir de apoio em um dado momento e não ser, aquele sinal digitado, reconhecido como integrado ao sistema 
daquela língua, conforme Battison (1978). Ele diz que a datilologia só se torna empréstimo lexical quando é reestruturada, ou seja, depois que adquire uma aparência mais adaptada à língua de sinais. Entretanto, autores como Lucas e Valli (2011) discordam de Battison e não consideram a datilologia, mesmo reestruturada, como empréstimo.

A maioria dos empréstimos linguísticos que entram nas línguas de sinais advêm de uma língua oral. Na libras, sinais como /NUNCA/, /TUDO/ e /SOL/, todos exemplos de datilologia, ilustram essa afirmativa, embora haja também empréstimos de sinais de outras línguas. Os sinais /ANO/, /SIM/ e /LIVRO/, por exemplo, são empréstimos da Língua de Sinais Americana (ASL), e os sinais /NASCER/, /ÁRVORE/ e /PALHAÇO/, da língua de sinais do Quebec (LSQ). De uma forma ou de outra, a datilologia ou digitação e o empréstimo de palavras das línguas orais para as línguas de sinais passam pela utilização da forma escrita para tornar possível a transferência.

\subsection{Translinguagem}

Garcia (2009) relata que o termo translinguagem foi primeiro cunhado por Cen Williams ao se referir a uma estratégia usada por professores para alternar entre os idiomas em salas de aula bilíngues, por exemplo, a leitura feita em uma língua e a escrita ou discussão em outra, com o objetivo de desenvolver a linguagem acadêmica de seus alunos. Garcia também usa o mesmo termo, mas em um sentido diferente. Para a ela, translinguagem vai além de uma estratégia de ensino, mas são as "práticas discursivas múltiplas" nas quais os indivíduos bilíngues se engajam a fim de significar seus mundos bilíngues (GARCIA, 2009, p.45).

Ao translinguarem, os alunos promovem discussões a respeito de um item de vocabulário, ou de um conceito específico, que vão além do empréstimo ou mudança de código, apesar de utilizá-los. Nesse sentido, o significado de translinguagem também excede o que Gutiérrez et al. (2001, p. 128) chamam de "uso híbrido da língua, visto como um processo de significação sistemático, estratégico e associativo". Numa perspectiva sociocultural, Garcia (2009) destaca que Blom e Gumperz (1972), assim como Valdés (1981), perceberam que as pessoas misturavam as línguas nas interações e até enunciados com fins comunicativos e sociais. Assim, translinguar é participar de discussões com os colegas, com fins acadêmicos ou não, misturando as línguas nessas 
interações, conjuntamente construindo ${ }^{5}$ significados como membros competentes de um grupo social.

Concordamos com Sayer (2013), a respeito da adequação do termo “translinguagem", com suas possíveis variações, pelos motivos por ele apresentado: primeiro, o termo sugere movimento através de um número indeterminado de línguas, e segundo porque o termo "translinguagem" capta o sentido de que a língua é um verbo e não um substantivo, e, portanto, deve ser vista como um ato social que as pessoas realizam, e não como um objeto linguístico que as pessoas possuem.

A translinguagem, como abordagem, pode ser vista como um constructo teórico, pois parece fornecer uma maneira de conceituar as práticas bilíngues dinâmicas que ultrapassam o âmbito da análise linguística, ou mesmo sociolinguística, da mudança de código. Apesar da mudança de código, do empréstimo e da translinguagem terem como característica comum o movimento linguístico de uma língua para outra, de acordo com Sayer (2013), é essa última, a translinguagem, que enfatiza o potencial das zonas liminares linguísticas dos bilíngues como um instrumento mediador de sentido.

\section{Aspectos metodológicos}

O estudo de caso é entendido como uma forma detalhada de investigação de um objeto ou fenômeno e de como ele se relaciona com o contexto no qual está inserido. Muito utilizado nas pesquisas em Ciências Sociais, foi adotado como método de investigação nas áreas de Linguagem e Educação a partir da década de 70.

Para Lüdke e André (1986), o estudo de caso como estratégia de pesquisa deve ser sempre bem delimitado, não importando se é simples e específico ou complexo e abstrato. Deve também ser contextualizado quanto a tempo e lugar, a fim de que uma investigação das circunstâncias possa ser realizada. André afirma que o estudo de caso representa um estudo exaustivo de uma unidade em particular a fim de compreendê-la em suas especificidades singulares, e deve ser um "retrato vivo da situação investigada, tomada em suas múltiplas dimensões e em sua complexidade própria” (1995, p. 55).

Essa pesquisa se caracteriza como um estudo de caso de caráter interpretativista, pois as ações sociais e seus significados são levados em conta no momento da análise dos dados (BORTONI-RICARDO, 2009). Os dados foram produzidos por duas alunas surdas (que chamaremos A1 e A2) e coletados em uma aula de língua portuguesa no curso de Letras-Libras da Universidade Federal de Goiás. Para tal, foi proposta uma 
tarefa colaborativa de produção de texto escrito em português a partir da seleção e ordenação de cinco gravuras e todo o diálogo foi gravado em vídeo, uma vez que se deu em libras.

Uma tarefa colaborativa pressupõe interação no sentido de "participação, envolvimento pessoal e tomada de iniciativas" (VAN LIER, 1988, p. 91), além de exigir que o aprendiz processe a língua de uma forma mais pragmática, dando atenção ao significado e fazendo uso do seu próprio conhecimento linguístico. Além do mais, o resultado alcançado deve ser passível de ser avaliado (ELLIS, 1999).

Especificamente no caso do ensino de línguas orais para alunos surdos, propomos tarefas escritas, porque nelas a habilidade linguística é desenvolvida, enquanto no exercício propriamente dito ela é pré-requisito, conforme distinção feita por Ellis (1994).

\section{Discussão dos dados}

Os trechos que serão discutidos são parte do diálogo estabelecido entre as alunas durante a realização de uma tarefa colaborativa de produção de texto. Ao longo da realização da tarefa, foi possível identificar o uso da datilologia, ocorrência de empréstimos, transferência e situações de translinguagem, que envolve todas as anteriores.

Para visualizar melhor a análise, optamos por escrever entre barras e letras maiúsculas o sinal (/SINAL/), entre apóstrofos e letras minúsculas, a palavra ('palavra'), em letras maiúsculas separadas por hífen, a palavra digitada (S-I-N-A-L), e entre parênteses, nossas inferências. Os números que antecedem os exemplos se referem respectivamente às linhas na transcrição das falas onde originalmente se encontra o recorte apresentado. Por motivo de espaço, serão mostrados aqui somente os trechos selecionados para a análise. Tentamos separar a análise dos dados por temas. Entretanto, em vários momentos, isso não foi possível, ocorrendo sobreposição.

\subsection{Datilologia}

A datilologia ou digitação em língua de sinais pode ser comparada à soletração em línguas orais e é utilizada em diferentes situações. O uso mais comum da datilologia é para dizer nomes de pessoas e lugares: 
105 A1. A mulher qual nome ? Por exemplo.

106 A2. (Pensa rapidamente) Sei lá. B-R-U-N-A.

Também é comum o uso da digitação da palavra em português logo após a realização do sinal, o que demonstra que a pessoa sinalizante conhece as duas formas correspondentes nas duas línguas. Nesse caso ocorre somente a datilologia ou digitação, e não empréstimo. Veja os trechos abaixo:

143 A1. Eu vou chamar policia. Eu vou telefonar chamar a policia:P-O-L-I-C-IA.

226 A2. É, com medo. Escreve aí. Depois ele deu azar A-Z-A-R ...a policia prendeu.

241 A2. Levar... L-E-V-A-R é verbo.

As alunas passam de uma língua para outra, compartilhando os significados das palavras e sinais e ao mesmo tempo, confirmando seu status bilíngue, conforme afirma Garcia (2009): um indivíduo bilíngue é uma pessoa que língua ${ }^{6}$ diferentemente. Neste outro trecho, A1 perguntou sobre um sinal cujo termo correspondente em português ela não conhecia. A2 digitou T-R-E-I-M-E-N-D-O (linha 154) duas vezes, com certa dúvida.

154 A2. T-R-E-I-M-E-N-D-O... T-R-E-I-M-E-N-D-O...

Uma palavra que não existe na língua portuguesa. A1 digitou, ela mesma, a palavra M-E-D-R-O-S-O e A2 não concordou, pois conhecia o significado do sinal e sabia que era diferente do significado da palavra 'medroso', embora não tivesse certeza da palavra correspondente a ele. Como a dúvida persistiu, novamente optaram pela omissão do léxico no texto, ressignificando a gravura dizendo que o homem fugiu assustado.

O termo em português que poderia corresponder ao sinal que fizeram era 'aflito', 'agitado'. Esse trecho também exemplifica uma situação de translinguagem. Mesmo no momento de incerteza, diante da escrita da palavra, ambas se posicionaram positivamente, assumindo que não estavam seguras sobre a forma correta da palavra 
(discussão a nível linguístico) e encontrando uma alternativa para resolver o conflito por meio da translinguagem, pois o processo envolveu, além do conhecimento linguístico de ambas, uma negociação de sentidos, relacionados à gravura e ao estágio onde se encontra o texto. No trecho seguinte:

256 A1. Falta palavra... Depois... Arrepender: A-R-R-E-P-E-N-D-E-R, aceitou mudar minha vida.

A1 digita a palavra para conferir se a grafia está correta. A2 confirma, digitando também. De novo elas translinguam, pois não há interrupção na fala e o movimento de ir e vir entre as línguas é contínuo. Novamente ratificam entre si suas posições bilíngues nesse contexto.

\subsection{Empréstimo}

Segundo Battison (1978), a datilologia só se torna empréstimo lexical quando é reestruturada, ou seja, depois que adquire uma aparência mais adaptada à língua de sinais. O sinal /OU/ nas linhas 125,129 e 208 se apresenta mais como um sinal do que como digitação, uma vez que o parâmetro de movimento foi incorporado à digitação, configurando uma reestruturação.

125 A1. O-U mulher encontrou A-C-H-O-U ele lá preso?

129 A1. OU...

208 A2. ... OU ela ligou chamou marido.

Neste outro exemplo, na linha 64, A1 telefona.

64 A1. Por exemplo: veja! A mulher vem andando, vê a janela, percebe que está quebrada...

E na linha seguinte:

65 A2. Eu V-O-U chamar. 
Por meio do empréstimo, a aluna explicita a marcação do tempo verbal, pois considera importante para a escritura do texto deixar clara a intenção da personagem. As formas do verbo 'ser' e 'estar' normalmente não aparecem explícitas na fala em libras. Por exemplo, a sentença em português: 'eu era gorda e agora sou magra', em libras seria algo como/EU ANTES GORD@AGORA MAGR@/. Além do não uso do verbo 'ser' e suas declinações, há também a omissão do sujeito quando ele é o mesmo da sentença antecedente. Na linha $65, \mathrm{~A} 2$ usa a forma verbal digitada $\mathrm{V}-\mathrm{O}-\mathrm{U}$ seguida de 'chamar', substituindo o futuro simples ('eu chamarei') no presente do indicativo.

Segundo Felipe e Monteiro (2008), a maioria dos verbos na libras apresentam forma neutra. O verbo "IR", além da forma neutra, possui também formas que marcam flexões pessoais e podem ser consideradas empréstimos da forma verbal em português, sendo representadas por sinais soletrados V-A-I e V- O-U ou pelo uso do parâmetro de direcionalidade.

Mesmo não havendo necessidade do uso do verbo "IR", em libras, A2 o inclui na sua fala por meio da digitação. Configura-se empréstimo porque, ao achar necessário transmitir a informação contida nessa forma verbal, que não é expressa na sua língua por meio de um sinal específico, mas por meio de referentes, como movimentação do corpo e outros mecanismos espaciais, A2 recorre à forma em português. Isso ocorre em outros momentos. A digitação dessas palavras não é feita de forma marcada (com pequenas pausas entre uma configuração de mão e outra) e sim com movimento fluido (sem interrupção), o que sugere o início de uma reestruturação nessa forma digitada. Outros exemplos que corroboram essa observação estão nos seguintes trechos:

143 A1. Eu vou chamar policia... Eu V-O-U telefonar, chamar a polícia P-O-L-ÍC-I-A.

152 A2. Eu V-O-U telefonar, chamar policia.

210 A2. Pessoa roubou ... V-O-U ligar, chamar a policia... Escreve aí.

214 A2. Estava assustado porque viu o cachorro. V-A-I morder... Matar?

181 A2. Ele fugiu correndo, porque cachorro V-A-I morder.

Nesse outro exemplo, a aluna retoma o uso do verbo 'ir', significando 'movimentar-se em direção à'. A1 digita a forma do verbo 'ir' ao sinalizar I-R /IGREJA/, e em seguida, digita outra forma do verbo 'ir', V-A-I /FUTURO/, como 
verbo auxiliar para marcar o tempo futuro, pois em libras essas marcações são feitas, a primeira, com o uso do sinal/IR/ e a segunda, pelo uso do sinal /FUTURO/.

259 A1. Depois futuro melhor I-R igreja. V-A-I... Futuro melhor. Trabalhar.

Na linha 201, o verbo 'ser' é digitado, ficando explícito na fala de A2.

201 A2. O cachorro / É / mau.

Enquanto na linha 84, A2 volta para libras: /AQUI ORDEM (está) ${ }^{7}$ CERTA / . Podemos ver o (não) uso do verbo 'estar', conforme é próprio da libras. É apenas um comentário de A2 e não faz parte do texto escrito. Novamente elas translinguam, demonstrando conhecer a estrutura das duas línguas e escolhendo, conforme acham necessário, a forma que melhor se aplica ao texto produzido e ao contexto da sua produção. Nessa direção, concordamos com Carvalho (1989) quando diz que o empréstimo é uma necessidade extralinguística em função de uma realidade.

No entanto, o trecho da linha 112 chamou a atenção porque, mesmo sinalizando toda a sua fala, A2 usa o sinal /DENTRO/ numa situação em que, normalmente, ele ficaria implícito na libras, sendo percebido ao longo da estrutura frasal.

112 A2. Então... Melhor ele roubou dinheiro /DENTRO/ do banco.

Como em português, o uso da preposição 'em', se referindo a lugar, é necessário. Ela transfere para libras esse uso e insere o sinal /DENTRO/ na sua fala. Nesse caso, fica evidente a interferência da língua portuguesa na produção da libras, e não a ocorrência de empréstimo, uma vez que na libras existe o sinal /DENTRO/ e no contexto onde ele foi empregado e que discutimos aqui, ele é dispensável.

\subsection{Translinguagem}

No diálogo abaixo transcrito, a digitação é usada para diferenciar em português o significado do sinal:

88 A1. Peraí... Estou pensando no título. Justiça (polícia ), preso (cadeia). 
89 A1. (Digita c-a-d-e-i-a) é?

90 A2. (Repete) C-A-D-E-I-A. É. Preso. C-A-D-E-I-A.

Aqui A2 faz uma pergunta para outro colega e A1 chama sua atenção.

91 A1. Não! Lembra? Só pode nós duas.

92 A2. Lembro. É mesmo. Certo. C-A-D-E-I-A. É isso. Justiça preso.

93 A1. (Balança afirmativamente a cabeça) Sim.

94 A2. P-R-E-S-O. Sabe... Português. Jeito próprio de surdo.

95 A1. P-R-E-S-O (Com dúvida, escreve enquanto A2 observa).

96 A2. Justiça e preso (Pega a borracha e apaga).

A digitação diferencia, portanto, o significado do sinal em /CADEIA/ e /PRESO/, que em libras, normalmente, se dá pelo contexto ou pelo acréscimo do sinal $/ L U G A R /+$ /PRESO/ para o termo 'cadeia' e o sinal /PESSOA/ + /PRESO/ para designar a pessoa que está presa. A dúvida surgiu em função do título, que A1 e A2 terminaram por não colocar no texto. A1 sinaliza /JUSTIÇA/, /POLÍCIA/ e /PRESO/ (linha 88) e em seguida questiona sobre a terminologia em português (linha 91).

Garcia (2009) declara que translinguar é participar de discussões com os colegas, coconstruindo significados como membros competentes de um grupo social. Numa perspectiva sociocultural, as pessoas misturam as línguas nas interações e até enunciados com fins comunicativos e sociais. É o que podemos ver na linha abaixo:

76 A1. Chama... Tem lei, L-E-I. Igual, por exemplo: eu roubo, aí chama a mulher que testemunhou, manda ela contar.

Nessa linha, além da movimentação entre as línguas por meio da datilologia, houve o compartilhamento de um conhecimento anterior de A1 com A2, com o objetivo de ajudá-la na construção de sentidos. Neste exemplo seguinte, A2 sinaliza e, em seguida, digita L-A-D-R- $\mathrm{A}-\mathrm{O}$.

110 A2. (cutuca A1) Ele homem roubou,L-A-D-R-Ã-O.

Da mesma forma, o sinal /ROUBAR/ pode ser usado como forma verbal ou nominal, dependendo do contexto ou de acompanhamento de outro sinal mais 
específico. No entanto, A2 optou por digitar. A1 então tece um comentário dizendo que há vários termos relacionados com o referido sinal, concordando com A2 em especificar qual o termo em português ela se referia. Nesse momento, ficou evidente a preocupação das alunas em esclarecer o significado do sinal bem como reafirmar entre si o status que o conhecimento dessa língua assegura, extrapolando o âmbito linguístico da discussão e passando para o lugar social que as pessoas surdas que conhecem a língua portuguesa ocupam na comunidade. Vejamos esse outro trecho.

125 A1. O-U mulher encontrou A-C-H-O-U ele lá preso?

126 A2. EU ACHO, me deixe ver.

127 A1. (Mostra o que escreveu.)

128 A2. Mulher viu janela quebrada eu A-C-H-O ele fugiu roubou banco ...pode... pode.

129 A1. O-U ...

130 A2. Porque ele está carregando saco nas costas. Olha. Roubou. Ta carregando.

132 A2. Por isso A-C-H-O que ele roubou banco. Não sei. (Ficam pensativas olhando para o texto.)

133 A1. Preso encontrou A-C-H-O-U encontrou A-C-H-O-U. Não é A-C-H-O, não é A-C-H-O.

134 A2. Preso viu nada como A-C-H-O-U? Não tem pessoa.

135 A1. (Em dúvida.) Não sei. Depende.

136 A2. Não sei.

137 A1. A-C-H-O-U, encontrou.. Aí percebeu que tinha fugido. Olha, assustou, ouviu barulho.

138Jogando pedra quebrou...

139 A2. (Fica quieta olhando gravura e A1 cutuca A2)

140 A1. E aí?

141 A2. Peraí... Mulher viu janela quebrada. Preso A-C-H-O ele fugiu.

Nesse trecho, novamente elas precisam discutir sobre o uso ambíguo das palavras 'encontrar' e 'achar', que em português podem ser sinônimas ('Eu 'encontrei' minha chave" e "Eu 'achei' minha chave"), e também o verbo 'achar', no sentido de 'ter 
opinião' (Eu acho que você não está certa). Em libras essa ambiguidade não acontece, uma vez que o sinal /ENCONTRAR/ e /ACHAR/ algo ou alguém e diferente do sinal /ACHAR/, ter opinião. Duas discussões acontecem paralelamente: uma sobre o sinal e outra a respeito da gravura. Como estavam negociando um possível sentido para a gravura, parece não se darem conta dessa consciência linguística em ambas as línguas. Vale ressaltar a contribuição da tarefa colaborativa no desenvolvimento linguístico do aluno uma vez que, ao interagir com o colega, faz-se necessário falar sobre a língua, o que implica em uma reflexão sobre a sua própria língua e a outra.

Perceber o movimento que os alunos fazem entre as línguas observando somente os seus aspectos linguísticos é desconsiderar os espaços discursivos criados a partir da interação que possibilitam aos alunos significarem cultural e socialmente o conteúdo que está sendo discutido. Ao translinguar, o aluno assume sua posição de pessoa bilíngüe, que se move entre as línguas, na sala de aula e fora dela, sempre que achar necessário dizer algo para o outro na outra língua, entendendo que dessa forma ambos irão significar melhor o conteúdo e, ao mesmo tempo, legitimizar sua identidade bilíngue e a do outro.

\section{Considerações finais}

Apresentamos nossas discussões sobre a mistura de línguas em contato num contexto de bilinguismo surdo onde a mudança de código representa uma capacidade bilíngue especial e não uma suposta deficiência linguística e consideramos que o indivíduo, nesse contexto, está sempre em processo de desenvolvimento linguístico. Como alguns autores reconhecem que a mistura de línguas não deve ser analisada somente no âmbito da descrição das modificações dos elementos linguísticos das línguas em contato, ousamos, baseadas no conceito da translinguagem proposto por García, que muda e amplia o foco da influência translinguística, investigar especificamente a influência da língua portuguesa na produção da libras, durante discussões realizadas para a produção de um texto escrito.

Observamos que as alunas surdas incluíram em suas falas elementos linguísticos próprios da língua portuguesa, os quais, ou não existem, ou são usados de forma distinta daquela empregada nas discussões, confirmando a influência dessa língua na libras, principalmente nesse contexto. Mais significativo ainda, foi perceber, conforme afirma Garcia (2009), como indivíduos bilíngues, com experiências diversas e desiguais em 
cada uma das duas línguas, translinguam, ou seja, se envolvem em práticas discursivas múltiplas e variadas que acentuam o potencial das zonas de contatos linguísticos daqueles indivíduos como um instrumento mediador e coconstrutor de sentido.

\begin{abstract}
The aim of this paper is to discuss the influence of Portuguese on the production of Libras in the translanguaging perspective, a concept presented by García (2009), for the contact of these languages results in a production that exceeds the traditional conceptual limits on the phenomena of languages in contact. It is an interpretive case study carried out through the analyses of a text written in Portuguese by two deaf students who sign Libras. The results showed the influence of Portuguese on Libras for the usage of linguistics elements belonging to Portuguese that neither exist nor are signed in Libras, but were included in the statements of the students during the discussions while producing the text. The analysis also revealed that the students, besides choosing to use the most appropriate modality (written or signed) and merge the languages, they also engaged in multiple discursive practices to cobuild meanings and social identities in their bilingual worlds, or they simply translanguaged.
\end{abstract}

Key words: Bilingualism, Portuguese. Libras. Translanguage

\title{
Resumen
}

El objetivo de este trabajo es reflexionar sobre la influencia de la lengua portuguesa en la producción de la lengua brasileña de signos (libras) desde la perspectiva de la translanguaging, pues el contacto de esas lenguas resulta en una producción que ultrapasa los limites conceptuales tradicionales sobre los fenómenos de las lenguas en contacto. Es un estudio de caso de carácter interpretativo, desarrollado a través de un análisis de texto, escrito en lengua portuguesa por dos alumnas sordas, hablantes de libras. Los resultados muestran la influencia de la lengua portuguesa en la libras, por intermedio de elementos lingüísticos, característicos de la lengua portuguesa $\mathrm{y}$, en libras, inexistentes o no aparentes en las prácticas de las alumnas durante discusiones para la producción de textos. El análisis de las discusiones también mostró que las alumnas, además de escoger usar la modalidad más apropiada (escrita o señalizada) y mesclar esas lenguas, se envolvieron en prácticas discursivas múltiples para construir, de forma conjunta (cobuild), significados y identidades sociales en sus mundos bilingües, o simplemente translanguaged.

Palabras-clave: Bilingüismo. Portugués. Libras. Translanguage.

\section{Referências}

ANDRÉ, M. E. D. A. Etnografia da prática escolar. Campinas, SP: Papirus, 1995.

AUER, P. The pragmatics of code-switching: a sequential approach. In: MILROY, L.; MUYSKEN, P. (Ed.). One speaker two languages: cross-disciplinary perspectives on code-switching. New York: Cambridge University Press, 1995. p. 115-135.

BATTISON, R.. Lexical borrowing in American Sign Language. Silver Spring, Md.: Linstok Press, 1978. 
BLOM, J.P. ; GUMPERZ, J.J. Social meaning in linguistic structures: code-switching in Norway. In: GUMPERZ, J.J.; HYMES, D. (Ed.). Directions in Sociolinguistic: the ethnography of communication. New YorK: Holt, Rinehart, Winston, 1972. p. 407434.

BLOOMFIELD, L. Language. New York: Henry Holt and Company, 1933.

BORTONI-RICARDO, S. M. Educação em língua materna: sociolinguística em sala de aula. 6 ed. São Paulo: Parábola Editorial, 2009.

CARVALHO, N. Empréstimos linguísticos. São Paulo: Ática, 1989.

ELLIS, R. The study of second language acquisition. London: Oxford University Press, 1994.

Benjamins, 1999.

Learning second language through interaction. Amsterdam: J.

FARIA-NASCIMENTO, S.P. Representações Lexicais da Língua de Sinais Brasileira: Uma Proposta Lexicográfica. Brasília: UNB, 290 f. Tese (doutorado) Instituto de Letras, 2009.

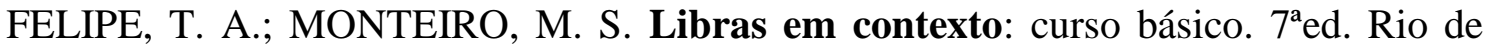
Janeiro: WallPrint, 2008.

FERNANDES, S. Avaliação em língua portuguesa para alunos surdos: algumas considerações. In: Secretaria de Educação do Estado do Paraná. Superintendência da Educação. Departamento de Educação Especial. Curitiba: SEED/SUED/DEE, 2007.

GARCIA, O. Bilingual and Translanguaging. In: GARCIA, O. Bilingual education in the 21st century: a global perspective. United Kingdom: Willey-Blackwell, p. 42-71, 2009.

GARCIA. O; WEI. L. Translanguaging: language, bilingualism and education. Basingstoke: Palgrave Macmillan, 2014.

GOFFMAN, E. Forms of talk. Oxford: Basil Blackwell, 1981.

GROSJEAN, F. Bilingual: Life and reality. Cambridge, Massachusetts, London: Harvard University Press, 2010.

GUMPERZ, J. J. Discourse strategies. Cambridge: Cambridge University Press, 1982.

GUTIÉRREZ, K. D., BAQUEDANO-LÓPEZ, P.; ALVAREZ, H. H.; Literacy as hybridity: moving beyond bilingualism in urban classrooms. In: REYES, M. L.; HÁlCON, J. J. (Ed.) The Best for our Children: Critical Perspectives on Literacy for Latino Students. . New York and London: Teachers College Press. 2001, p.122-141 
HAUGEN, E. The ecology of language. Stanford: Stanford University Press, 1972. Disponível em:

http://history.lzu.edu.cn/editor/asp/upfiles/file/201504/20150413155755110.pdf>. Acesso em: 13 ago. 2015.

JACOBSON, R. Can two languages be developed concurrently? Recent developments in bilingual methodology. In: Altman, H. B.; MCCLURE, M. G. (Ed.). Proceedings of the 18th southern conference on language teaching. Atlanta, GA: Southern Conference on Language Teaching, Spelman College, 1983. p. 110-132.

JACOBSON, R.; FALTIS, C. Language distribution issues in bilingual schooling. Clevedon: Multilingual Matters, 1990.

LUCAS, C; VALLI, C. Language contact in the American deaf community. In: VALLI, C.; LUCAS, C.; MULROONEY, K. J.; VILLANUEVA, M. Linguistics of American Sign Language: an introduction. 5. ed. Washington, DC: GallaudetUniversity Press, 2011. p.542-564.

LÜDKE, M; ANDRÉ, M. E. D. A. Pesquisa em educação: abordagens qualitativas. São Paulo: E.P.U., 1986.

MACNAMARA, J. The bilingual's linguistic performance: a psychological overview. Journal of Social Issues. v. 23, n. 2, p. 58-77, 1967.

MACKEY, W. The Description of Bilingualism. In: WEI, L. The bilingualism reader. London: Routledge, 2000.

MELLO. H. A. B. Educação bilíngue: uma breve discussão. Horizontes de Linguística Aplicada, v. 9, n.1, p. 118-140, 2010.

NASCIMENTO, C. B. Alfabeto Manual da Língua de Sinais Brasileira (LIBRAS): uma fonte produtiva para importar palavras da língua portuguesa. Revista Trama, v. 7, n. 14, p. 33- 55, 2011.

POPLACK, S. Sometimes I'll start a sentence in Spanish y termino en Español: toward a typology of code-switching. Linguistics, v. 18, n. 7/8, p. 581-618, 1980.

QUADROS, R.M.; KARNOPP, L. B. Língua de Sinais Brasileira: Estudos linguísticos. Porto Alegre: Artmed, 2004.

QUADROS, R.M. O bi do bilingüismo na educação de surdos In: Surdez e bilinguismo. Porto Alegre: Editora Mediação, v. 1, p. 26-36, 2005.

QUADROS, R.M; PIMENTA, N. Curso de Libras1. Rio de Janeiro: LSB Video, 2006.

SAYER, P.. Translanguaging, TexMex, and Bilingual Pedagogy: Emergent Bilinguals Learning Through the Vernacular. TESOL QUARTERLY, v. 47, n. 1, mar 2013.

WEINREICH, U. Languages in contact. The Hague: Mouton, 1974. 
THOMASON, S. G.; KAUFMAN, T. Language contact, creolization and genetic linguistics. Berkeley: University California Press, 1988.

VALDÉS, G. Code-switching as a deliberate verbal strategy: a microanalysis of direct and indirect requests among Chicano bilingual speakers. In: DURAN, R. (Ed.) Latino languageandccommunicativebehavior. Nowoodm New Jersey: Ablex, 1981. p. 95108.

VAN LIER, L. The classroom and the language learner. Essex: Longman, 1988.

ZENTELLA, A. C. Growing up bilingual: Puerto Rican children in New York. Malden, MA: Blackwell, 1997.

\footnotetext{
Notas

${ }^{1}$ Considerando que a libras e o português têm o mesmo status linguístico, ambas as línguas serão grafadas em letras minúsculas.

${ }^{2}$ Para o surdo brasileiro, a libras é a sua língua natural e o português, sua segunda língua, que exige um processo formal para sua aprendizagem (QUADROS, 2005; FERNANDES, 2007).

${ }^{3}$ Instituto de Patrimônio Histórico e Artístico Nacional (IPHAN). Estudos Preliminares para o Inventário Nacional da Diversidade Linguística (INDL). Disponível em:

http://portal.iphan.gov.br/pagina/detalhes/981/ Acesso em: 2 nov. 2017.

${ }^{4}$ Com o intuito de tornar a leitura mais simples, os trechos originalmente em inglês citados nesse trabalho foram traduzidos pela autora.

${ }^{5} \mathrm{O}$ termo originalmente utilizado em inglês é coconstruction.

${ }^{6}$ Para Ofélia Garcia, o termo "língua" também pode ser usado como verbo.

${ }^{7}$ Forma não explicitada em libras.
} 